\title{
HIGH SPECIFIC ENERGY LITHIUM CELLS FOR SPACE EXPLORATION
}

\author{
F. Farmakis (1), N. Georgoulas (1), I. Karafyllidis (1), I. Amoiridis (1), C. Elmasides (1), S. \\ Balomenou ${ }^{(2)}$, \\ D. Tsiplakides ${ }^{(2)}$, M. Nestoridi ${ }^{(3)}$ \\ (1) Democritus University of Thrace, Kimmeria Campus 67100 Xanthi, Greece, Email: farmakis@ee.duth.gr \\ (2) CERTH, $6^{\text {th }} \mathrm{km}$. Charilaou-Thermi Rd., GR570 01, Thermi, Thessaloniki, Greece, Email: stellab@,cperi.certh.gr \\ (3) ESA/ESTEC, PO Box 299, 2200 AG Noordwijk, The Netherlands, Email: Maria.Nestoridi@esa.int
}

\begin{abstract}
The paper discusses development under an ESA TRP activity (Contract No. 4000109879/13/NL/LvH) with a target of high specific energy Lithium-ion cells, capable of operating under low temperature conditions, i.e. -40 ${ }^{\circ} \mathrm{C}$. Such cells may be encountered in future exploration missions, which do not consider the use of Radioisotope Heater Units. During the activity, $\geq 1$ Ah silicon-based high energy density prototype cells, following components characterization and optimization, were designed, developed, manufactured and tested under room and subzero temperature conditions down to $-40{ }^{\circ} \mathrm{C}$.

The developed and tested prototype cells exhibited energy density of around $208 \mathrm{Wh} / \mathrm{Kg}$ at room temperature under $\mathrm{C} / 10$ charge-discharge rate within voltage range of $2.8 \mathrm{~V}$ and $4.1 \mathrm{~V}$. Moreover, the prototype cells could retain and deliver more than $75 \%$ of their capacity at room temperature upon cycling at $-40{ }^{\circ} \mathrm{C}$, demonstrating an energy density of $140 \mathrm{Wh} / \mathrm{kg}$.
\end{abstract}

\section{LITERATURE SURVEY FOR CELL COMPONENTS}

A thorough literature and patent survey was conducted regarding materials (anodes, cathodes, electrolytes) for low temperature Li-ion batteries. Currently, the state-ofthe-art space qualified batteries by European manufactures can reach up to $155 \mathrm{Wh} / \mathrm{kg}$ (at C/2) at $25{ }^{\circ} \mathrm{C}$ [1], and provide satisfactory performance in cycling only down to $0{ }^{\circ} \mathrm{C}$. Below $0{ }^{\circ} \mathrm{C}$ the charging of these $\mathrm{Li}$-ion batteries is the main limitation. The current solution in order to charge the battery is the use of external power and heaters to bring the cell to relatively high temperatures since there is no electrochemical system that can efficiently charge at low temperature. However, the use of external heaters decreases system efficiency and robustness while increasing its complexity and weight.

\subsection{Anodes}

The most important rival to the graphite anode is silicon (or silicon-based materials), thanks to its excellent theoretical specific capacity (around 3800 $\mathrm{mAh} / \mathrm{g}$ at room temperature, RT). However, even though silicon delivers a high galvanostatic capacity, it suffers from capacity decrease during cycling (cycle fading). Until now, it has been shown that this capacity fading against cycling is due to the volume change during lithiation and delithiation that can exceed 300\% of its initial volume. Various technological approaches have been attempted that have as goal to enhance the mechanical integrity of silicon [2]. Nanostructured silicon, silicon-carbon composites, binders and adhesion layers are some of the attempts that are presented. Some of the proposed solutions are promising, but they appear complex and difficult to implement in a production line. Our approach was to develop amorphous silicon film in micro-grain structure.

\subsection{Cathodes}

Today's technologically important cathodes fall into two broad categories: metal oxides and polyanionic compounds [3]. In general, it is accepted that the cathode kinetics (lithium intercalation) dominate the generally poor rate capability of $\mathrm{Li}$-ion cells at low temperatures. Therefore cathodes with high specific capacity and rate capability at subzero temperatures should be identified.

\subsection{Electrolytes}

Most compositions of lithium electrolytes are based on solutions of one or more lithium salts in mixtures of two or more solvents. The rationale behind this mixed solvent formulation is that the diverse and often contradicting requirements of battery applications can hardly be met by any individual compound. Low temperature performance represents a significant challenge for Li-ion battery electrolyte solutions. To improve the temperature range of operation of lithiumion cells, modification of the electrolyte formulation is practiced through the use of (a) optimized solvents blends, (b) use of novel co-solvents, (c) the use of electrolyte additives, and (d) use of novel electrolyte salts, to achieve improved cell resilience to warm temperature exposures.

In view of these, we focused on the development of electrolytes that are capable to operate under sub-zero temperatures. Formulations were based on $\mathrm{LiPF}_{6}$ solutions of carbonates with the addition of a low 
freezing point agent and a SEI former.

\section{ELECTRODES AND LOW TEMPERATURE ELECTROLYTES CHARACTERIZATION}

The development of the silicon anode and the low temperature electrolyte was conducted by preparing and testing small Swagelok ${ }^{\circledR}$ T-type half and full cells.

\subsection{Graphite and Silicon-based anodes}

Two types of anodes have been evaluated: (i) "standard" commercial graphite anode and (ii) silicon ones. The physicochemical characteristics of the produced Si were assessed by profilometry, conductivity measurements and Scanning Electron Microscopy (SEM). A number of techniques were applied in order to evaluate the performance and electrochemical characteristics of the fabricated materials and cells (in the form of Swagelok ${ }^{\circledR}$ T-type half and full cells), including galvanostatic cycling, cyclic voltammetry and Electrochemical Impedance Spectroscopy (EIS).

\subsection{Cathode electrodes}

Metal-based oxide cathodes were procured, from different Suppliers, and were deployed in Swagelok ${ }^{\circledR}$ T-type half and full cells. The main conclusion from the electrochemical characterization of cathodes was that electrodes received from Supplier 1 exhibited high specific capacity values at room temperature (190 $\mathrm{mAh} / \mathrm{g}$ ) with more than $2 \mathrm{mAh} / \mathrm{cm}^{2}$. When half-cells were cycled at subzero temperatures excellent performance was obtained even at $-40{ }^{\circ} \mathrm{C}$ with a specific capacity of more than $50 \mathrm{mAh} / \mathrm{g}$ (or $0.7 \mathrm{mAh} / \mathrm{cm}^{2}$ ). Those results were highly promising and therefore the above mentioned electrodes (from Supplier 1) were used for the construction of full cells.

\subsection{Development and characterization of low temperature Electrolytes}

A series of electrolyte formulations for low temperature (LT) operation were prepared. As reference, a commercial carbonate-based electrolyte was used. The conductivities of the electrolytes were measured at the temperature range of $-40{ }^{\circ} \mathrm{C}$ to $25{ }^{\circ} \mathrm{C}$. Fig. 1 summarizes the conductivities for all electrolyte samples at the two extreme $\left(25^{\circ} \mathrm{C}\right.$ and $\left.-40{ }^{\circ} \mathrm{C}\right)$ and one intermediate $\left(-10{ }^{\circ} \mathrm{C}\right)$ temperature. The main conclusions form these data are the following:

- The conductivity of all samples at $25{ }^{\circ} \mathrm{C}$ is comparable to the standard solution.

- The conductivity of standard (reference) solution, without the addition of any anti-freezing agent, dropped to practically zero value for temperatures below $-20{ }^{\circ} \mathrm{C}$, suggesting that the solution was frozen.

- All modified electrolytes showed better performance. The highest conductivity at $-40{ }^{\circ} \mathrm{C}$ was performed by sample 32, implying a major advantage of this composition for low temperature applications.

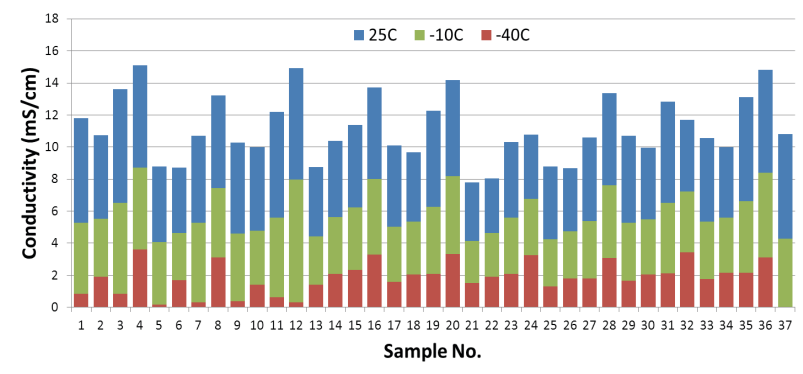

Figure 1. Conductivities of all modified electrolytes at $25^{\circ} \mathrm{C},-10^{\circ} \mathrm{C}$ and $-40^{\circ} \mathrm{C}$.

\subsection{Full Cells Characterization}

Based on the results and analysis for single elements (anodes, cathode, LT electrolytes), full cells with $\mathrm{Si}$ anode and selected cathode with best performing electrolytes (designated as $32 *$ and $20 *$ ) were built and all relevant electrochemical and performance tests were conducted under RT to subzero temperatures.

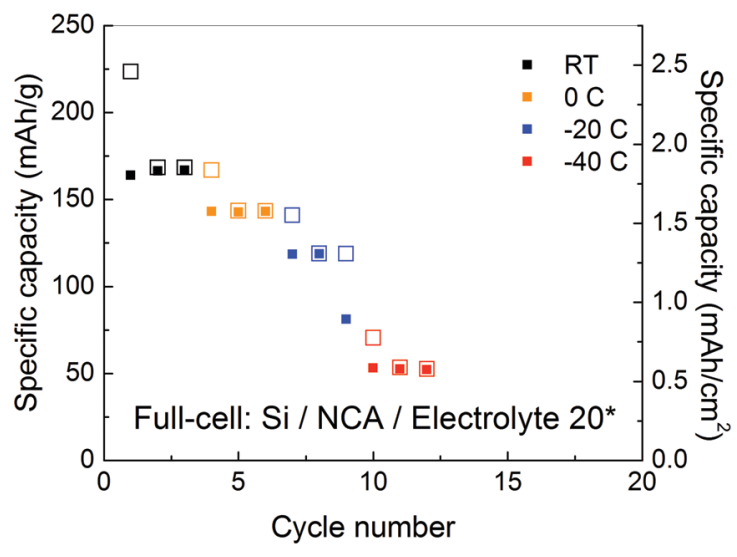

Figure 2. Specific capacity of Swagelok ${ }^{\circledR}$ full cells with electrolyte $20^{*}$ at various temperatures. Symbols: opencharging, closed-discharging

After activating the cells and performing 3 cycles at $\mathrm{RT}$ at $\mathrm{C} / 10$, they were subjected to various low temperatures $\left(0,-20,-40{ }^{\circ} \mathrm{C}\right)$ for three galvanostatic cycles with the same current than the RT. It is shown (Fig. 2) that the electrochemical system with $20 *$ LT electrolyte provides excellent results at low temperatures. More specifically, the cells are able to charge and discharge even at $-40{ }^{\circ} \mathrm{C}$ delivering around $1 / 3$ of the capacity at RT.

As verification for the absence of Li plating during lithiation, the voltage between the silicon anode and a lithium reference electrode was monitored. Fig. 3 shows the voltage between the anode and the $\mathrm{Li}$ reference electrode during charging and discharging at various temperatures. It is evident that this voltage is always above zero, when the full cell voltage attains 
4.1 $\mathrm{V}$, and thus we can assume that no Li plating occurs in this voltage.

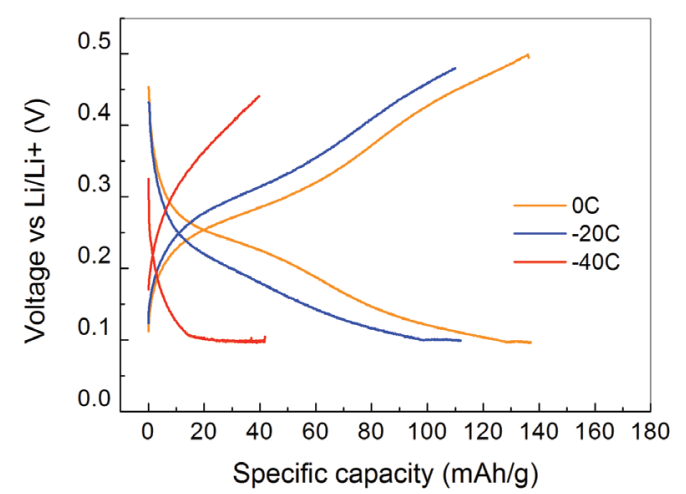

Figure 3. Voltage between Si anode and Li reference electrode in a full cell at various temperatures during charging and discharging.

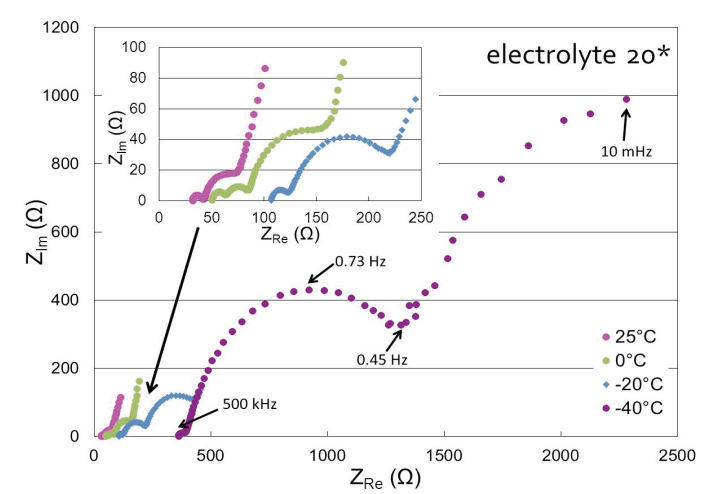

Figure 4. Electrochemical Impedance for full cell with electrolyte $20^{*}$ at various temperatures.

EIS performed at full cell at various temperatures shows three semicircles for $\mathrm{T}<0{ }^{\circ} \mathrm{C}$ (Fig. 4).

The small semicircle in HF region was ascribed to the migration of lithium-ion through SEI film as well as contact problems, the semicircle in the MF region was attributed to the electronic properties of the material, and the semicircle in the LF region was related to charge transfer process, while the inclined line in the LF region (frequency $<0.45 \mathrm{~Hz}$ ) represents, as in all Nyquist plots, the solid state diffusion.

\section{DEVELOPMENT OF PROTOTYPE CELLS AND EVALUATION}

Two versions of prototype cells (both 0.4 Ah and 1 Ah) were developed and tested: Prototypes V1 and V2. Materials were chosen according to the results of materials' performance and electrochemical characterizations on T-type cells. At first a prototype cell was manufactured and tested and finally a modification was designed, manufactured and tested in order to further improve the assembly procedure, enhance leakage control, and lead to smaller and lighter packaging for the cells. The basic design of the prototype cell is illustrated in Fig. 5 . The cell case is made from polypropylene, and the poles from copper and aluminum for anode and cathode, respectively. A finite element analysis was conducted in order to provide an improved geometry model.

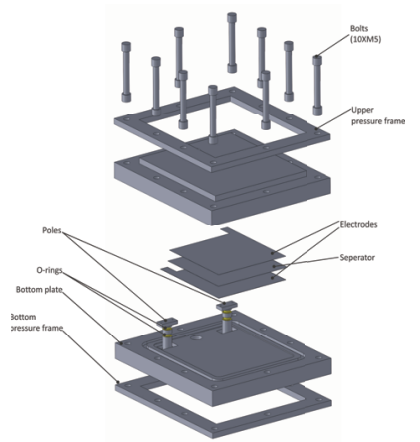

Figure 5. Breakdown of the 3D drawing of the prototype cell.
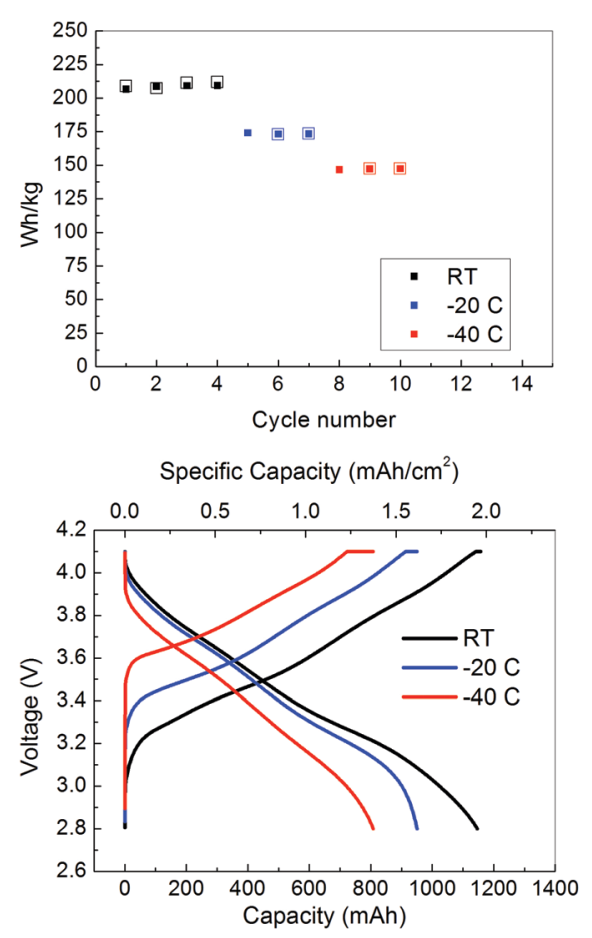

Figure 6. Specific energy as a function of cycling at RT, $-20{ }^{\circ} \mathrm{C}$ and $-40{ }^{\circ} \mathrm{C}$ (top) and the relevant voltage vs capacity profiles for the 3 rd cycle (bottom). Symbols: open-charging, closed-discharging

Galvanostatic cycling at room temperature was conducted to activated cells between $4.1 \mathrm{~V}$ and $2.8 \mathrm{~V}$ at $\mathrm{C} / 10$ and $\mathrm{C} / 15$ discharging and charging rate, respectively. Following, charge/discharge cycles were performed at low temperatures, down to $-40{ }^{\circ} \mathrm{C}$. As shown in Fig. 6, the 1 Ah cell demonstrate capacity of more than $1 \mathrm{Ah}$ and more than $200 \mathrm{Wh} / \mathrm{Kg}$ of specific energy. In addition, the cell can effectively provide more than $1.0 \mathrm{mAh} / \mathrm{cm}^{2}$ at low temperatures down to $-40{ }^{\circ} \mathrm{C}$ 
and they retain more than $70 \%$ of the RT capacity. Further to this direction, two (2) new V2 prototypes (0.4 $\mathrm{Ah}$ and 1.0 Ah of nominal capacity) were tested in cycling tests. The performance of the $1.1 \mathrm{Ah}$ cell at BoL at RT and $-40{ }^{\circ} \mathrm{C}$ is shown in Fig. 7. The cells achieved an energy density of $207 \mathrm{Wh} / \mathrm{kg}$ and $160 \mathrm{Wh} / \mathrm{kg}$, respectively. The cycling performance of the cell at -40 ${ }^{\circ} \mathrm{C}$ is demonstrated in Fig. 8. Up to 45 cycles, the capacity remains stable and up to $75 \%$ of its initial value at RT. When cycling further progresses, the cell's capacity rapidly fade down to zero. There are several possible explanations, such as $\mathrm{Si}$ anode or cathode damage, short circuit due to Li dendrites, electrolyte decomposition, packaging failure etc. The latter is evident even after simple visual inspection of the cells following cycling testing (post mortem analysis).

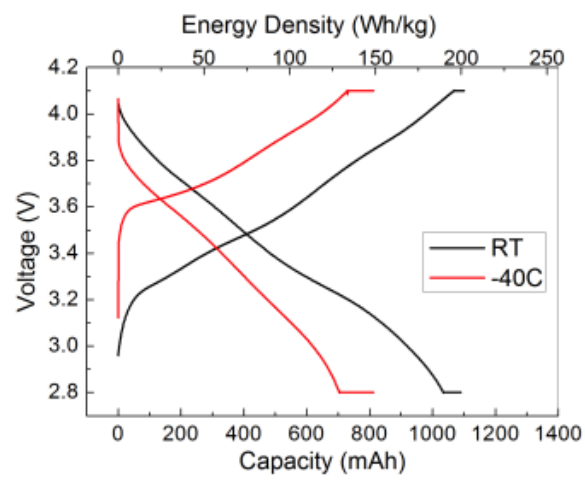

Figure 7. Voltage-capacity profile at BoL at C/10 at RT and $-40{ }^{\circ} \mathrm{C}$.

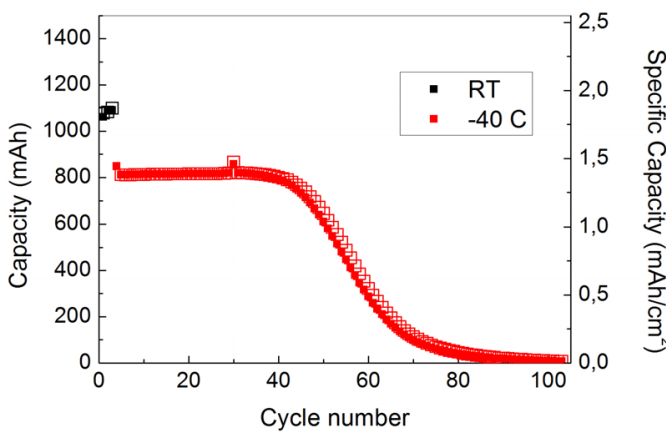

Figure 8. Capacity as a function of galvanostatic cycling at $-40^{\circ}$ C. Symbols: open-charging, closeddischarging

During cycling, the internal resistance (IR drop) of the cells was determined by the current interruption (or current-off) method. The results are summarized in Fig. 9.

The main conclusions are the following:

1. The ohmic resistance exhibits a stable performance (IR depends weakly on \% DoD) for the first 40-50 cycles. After that, the behaviour changes and the ohmic resistance at low $(0 \%)$ and high $(100 \%)$ $\mathrm{DoD}$ is significantly higher than that at intermediate DoD values.

2. The increase in ohmic resistance is in accordance with the performance (cycling capacity test) of the cell and concomitant capacity fades down.

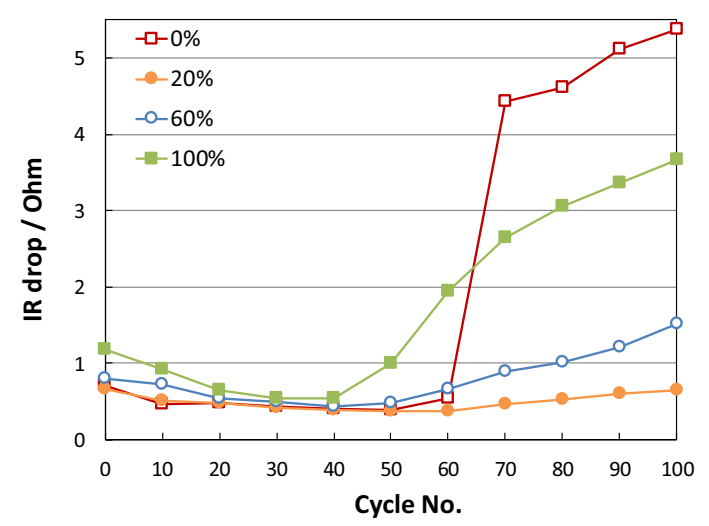

Figure 9. Ohmic resistance evolution during cycling at $-40{ }^{\circ} \mathrm{C}$ and at different $\% \mathrm{DoD}$.

\section{CONCLUSIONS}

During this activity, silicon-based high energy density prototype cells with 1 Ah nominal capacity, following components characterization and optimization, were designed, developed, manufactured and tested under room and subzero temperature conditions down to -40 ${ }^{\circ} \mathrm{C}$. The cells exhibit energy density of around 208 $\mathrm{Wh} / \mathrm{Kg}$ (cell chemistry is considered) at room temperature under $\mathrm{C} / 10$ charge-discharge rate within voltage range of $2.8 \mathrm{~V}$ and $4.1 \mathrm{~V}$. Moreover, the prototype cells could deliver more than $75 \%$ of their capacity at room temperature when cycled at $-40{ }^{\circ} \mathrm{C}$ (C/15 charge and $\mathrm{C} / 10$ discharge rate), demonstrating an energy density of $140 \mathrm{Wh} / \mathrm{kg}$.

To our knowledge, these results are the best reported in terms of capacity retention at $-40{ }^{\circ} \mathrm{C}$ at high energy cells $(>200 \mathrm{Wh} / \mathrm{kg})$.

\section{REFERENCES}

1. Ratnakumar, B.V. \& Smart, M.C. (2010). Lithium Plating Behavior in Lithium-ion Cells. ECS Transactions, 25(36), 241-252.

2. Liang, B., Liu, Y. \& Xu, Y. (2014). Silicon-based materials as high capacity anodes for next generation lithium ion batteries. J. Power Sources, 267, 469-490.

3. Doeff, M. M. (2012). Encyclopedia of Sustainability Science and Technology. Springer, New York. 